\title{
Nghiên cứu mối quan hệ giữa chất lượng dịch vụ, hình ảnh thương hiệu, giá trị nhận được, niềm tin, sự hài lòng, và lòng trung thành của khách hàng cá nhân trong ngành ngân hàng
}

\section{Research the relationship between service quality, brand images, value received trust, satisfaction, and loyalty in banking sector}

\author{
Ngô Đức Chiến ${ }^{1 *}$ \\ ${ }^{1}$ Trường Đại học Kiến Trúc Đà Nẵng, Việt Nam \\ *Tác giả liên hệ, Email: chiennd@ dau.edu.vn
}

THÔNG TIN

DOI: $10.46223 / \mathrm{HCMCOUJS}$.

econ.vi.16.2.774.2021

Ngày nhận: 13/08/2020

Ngày nhận lại: 22/09/2020

Duyệt đăng: 01/10/2020

Tù khóa:

chất lượng dịch vụ; sự hài lòng; niềm tin; lòng trung thành

Keywords:

service quality; satisfaction; trust; loyalty

\section{TÓM TẮT}

Nghiên cứu này tập trung xác định mối quan hệ giữa các nhân tố Chất lượng dịch vụ, Hình ảnh thương hiệu, Giá trị nhận được, Niềm tin, Sự hài lòng và Lòng trung thành của khách hàng cá nhân trong ngành ngân hàng. Thông qua các phép phân tích cơ bản từ thống kê cho đến mô hình SEM, với dữ liệu khảo sát từ 327 cá nhân có giao dịch tại các Ngân hàng thương mại trên địa bàn Thành phố Đà Nẵng. Kết quả cho thấy, (1) Nhân tố CL (Chất lượng dịch vụ) tác động tích cực đến HA (Hình ảnh thương hiệu), GD (Giá trị nhận được), NT (Niềm tin); (2) Nhân tố HA (Hình ảnh thương hiệu) tác động tích cực đến NT (Niềm tin), HL (Sự hài lòng); (3) Nhân tố NT (Niềm tin), GD (Giá trị nhận được) tác động tích cực đến HL (Sự hài lòng) và (4) Nhân tố CL (Chất lượng dịch vụ), HA (Hình ảnh thương hiệu), NT (Niềm tin), HL (Sự hài lòng) tác động tích cực đến TT (Lòng trung thành).

ABSTRACT
This study focuses on defining the relationship between
Service Quality, Brand Images, Value Received, Trust,
Satisfaction, and Loyalty of individual customers in the banking
industry. Through the basic analysis from statistics to SEM
model, with survey data from 327 individuals with transactions
at commercial banks in Danang City. The results show that (1)
CL (Service Quality) positively affects HA (Brand Image), GD
(Value Received), NT (Trust); (2) HA (Brand Image) positively
affects NT (Trust), HL (Satisfaction); (3) NT (Trust), GD
(Value Received) positively impact HL (Satisfaction) and (4)
CL (Service Quality), HA (Brand Image), NT (Trust), HL
(Satisfaction) positively affect TT (Loyalty).

\section{Giới thiệu}

Trong bối cảnh cạnh tranh gay gắt như hiện nay, việc giữ chân và thu hút khách hàng quay trở lại giao dịch và tiếp tục sử dụng các sản phẩm/dịch vụ của một tổ chức là điều rất cần 
thiết. Chính vì vậy, nhiều tổ chức đã tiến hành các biện pháp như quảng cáo, các chương trình tiếp thị và ban hành các chính sách khuyến mãi; tuy nhiên hầu hết các hoạt động này đều cần phải có một chi phí khá cao mà không ít các tổ chức không thể thực hiện được trong một thời gian dài. Xuất phát từ nguyên nhân đó, nhiều tổ chức đã nhận thức được rằng, việc gia tăng chất lượng dịch vụ là điều kiện rất cần thiết trong việc gia tăng sự hài lòng của khách hàng và thúc đẩy khách hàng tiếp tục gia tăng sử dụng các sản phẩm/dịch vụ của tổ chức mà không gây tốn kém quá nhiều chi phí và tạo nên các lợi ích cho các tổ chức trong việc phát huy tối đa nguồn nhân lực sẵn có của mình (Omoregie, Addae, Coffie, Ampong, \& Ofori, 2019).

Nâng cao chất lượng dịch vụ là điều kiện tiền đề trong việc thúc đẩy sự hài lòng cũng như lòng trung thành của khách hàng, không những thế các vấn đề về hình ảnh thương hiệu, niềm tin và giá trị nhận được xem là những yếu tố góp phần tích cực trong việc gia tăng lòng trung thành của khách hàng (Hurley, Gong, \& Waqar, 2014; Jarvinen, 2014; Omoregie et al., 2019). Lòng trung thành được xem là sự gắn kết của một cá nhân với một tổ chức hay sự lặp đi lặp lại về việc sử dụng các sản phẩm/dịch vụ của tổ chức nào đó (Omoregie et al., 2019).

Do đó, việc nghiên cứu mối quan hệ giữa Chất lượng dịch vụ, Hình ảnh thương hiệu, Niềm tin và Lòng trung thành của khách hàng là điều rất cần thiết và được thực hiện bởi nhiều nhà nghiên cứu trong và ngoài nước. Chính vì vậy, tác giả đã thực hiện việc nghiên cứu "Nghiên cứu mối quan hệ giữa các nhân tố Chất lựng dịch vụ, Hình ảnh thương hiệu, Giá trị nhận được, Niềm tin, Sụ hài lòng và Lòng trung thành của khách hàng cá nhân trong ngành ngân hàng" để tiến hành nghiên cứu và phân tích.

\section{Cơ sở lý thuyết}

\subsection{Một số khái niệm}

\subsubsection{Khái niệm về chất luợng dịch vu}

Theo Parasuraman, Zeithaml, và Berry $(1985,1988)$, định nghĩa chất lượng dịch vụ là "mức độ khác nhau giữa sự mong đợi của người tiêu dùng về dịch vụ và nhận thức của họ về kết quả của dịch vụ”, "Chất lượng dịch vụ là khoảng cách giữa sự mong đợi (kỳ vọng) của khách hàng và nhận thức (cảm nhận) của họ khi đã sử dụng qua dịch vụ”. Định nghĩa này đã được giới học giả và quản trị chấp nhận, sử dụng rộng rãi vào nghiên cứu cũng như ứng dụng thực tế. Chất lượng dịch vụ là một cấu trúc đa chiều bao gồm năm thành phần, đó là mức độ tin cậy, sự đảm bảo, phương tiện hữu hình, mức độ đồng cảm và mức độ đáp ứng (Lovelock \& Wirtz, 2011; Parasuraman et al., 1985, 1988; Wu, Tsai, Hsiung, \& Chen, 2015).

\subsubsection{Khái niệm về hình ảnh thuơng hiệu}

Hình ảnh thương hiệu đề cập đến ấn tượng chung được tạo ra trong tâm trí khách hàng hoặc công chúng về một tổ chức cụ thể dựa trên các khía cạnh như tên tổ chức, sản phẩm/dịch vụ và sự tương tác giữa tổ chức và khách hàng (Aydin \& Ozer, 2005; Wang, 2010). Tương tự, hình ảnh thương hiệu liên quan đến mọi thứ mà mọi người liên kết với tổ chức (Hussain, Nasser, \& Hussain, 2015; Zameer, Tara, Kausar, \& Mohsin, 2015). Nó liên quan đến nhận thức, suy luận và niềm tin mà mọi người biết về một tổ chức (Abd-El-Salam, Shawky, \& El-Nahas, 2013; Hu, Kandampully, \& Juwaheer, 2009). Jha, Deitz, Babakus, và Yavas (2013) đề xuất rằng hình ảnh thương hiệu không thể được chia sẻ nhất trí giữa các bên liên quan của tổ chức; ngụ ý rằng nó thay đổi theo tính chất của các bên liên quan đến tổ chức. Hình ảnh thương hiệu có liên quan mạnh mẽ đến danh tiếng của tổ chức. Mặc dù các thuật ngữ thường được sử dụng thay thế cho nhau, hình ảnh của tổ chức là liên quan đến ngắn hạn trong khi danh tiếng của tổ chức là liên quan đến dài hạn (Omoregie et al., 2019). Theo Kant và Jaiswal (2017) hình ảnh thương hiệu bao 
gồm hai thành phần chính là chức năng và cảm xúc; trong đó, chức năng bao gồm các đặc điểm hữu hình có thể dễ dàng đo lường và đánh giá; còn cảm xúc bao gồm niềm tin và cảm xúc (tình cảm) mà một cá nhân có đối với tổ chức.

\subsubsection{Khái niệm về niềm tin}

Niềm tin rất quan trọng đối với mối quan hệ khách hàng cá nhân với doanh nghiệp nói chung và với ngân hàng nói riêng. Niềm tin sẽ dẫn đến giao dịch của khách hàng thuận tiện hơn. Khách hàng không phải lo lắng về lợi ích cá nhân của họ được chăm sóc, tiền tiết kiệm của họ với ngân hàng và các sản phẩm dịch vụ mà họ đã sử dụng hoặc dự định sử dụng từ ngân hàng. Ở một mức độ nhất định, niềm tin cao sẽ dẫn đến khách hàng có thể "tha thứ" nếu sử dụng một dịch vụ của ngân hàng chưa được chuẩn mực và coi đó là một ngoại lệ đối với một ngân hàng được đặt niềm tin. Tuy nhiên, với niềm tin thấp thì trải nghiệm khi sử dụng một dịch vụ ngân hàng chưa chuẩn mực có thể được coi là "bằng chứng" mà ngân hàng đó không được tin cậy. Do khủng hoảng tài chính, niềm tin vào các hệ thống ngân hàng, niềm tin vào ngân hàng đã giảm ở nhiều nước (Hurley et al., 2014; Jarvinen, 2014). Theo Jarvinen (2014) niềm tin của khách hàng dựa trên kinh nghiệm của khách hàng và phụ thuộc vào khả năng của các ngân hàng hành xử một cách đáng tin cậy, tuân thủ các quy tắc, làm việc tốt và phục vụ lợi ích chung.

\subsubsection{Khái niệm về lòng trung thành của khách hàng}

Lòng trung thành của khách hàng đối với hoạt động ngân hàng bán lẻ là sự cam kết mạnh mẽ và sẵn sàng liên tục lặp lại sự quay trở lại để sử dụng của một sản phẩm hoặc dịch vụ trong thời gian dài (Tweneboah-Koduah \& Farley, 2015). Lam, Shankar, Erramilli, và Murthy (2004) định nghĩa lòng trung thành của khách hàng là sự lặp đi lặp lại của khách hàng về việc sử dụng các sản phẩm, dịch vụ của nhà cung cấp. Trong những năm gần đây, lòng trung thành của khách hàng đối với dịch vụ ngân hàng đã trở thành tâm điểm của các nhà tiếp thị và nhà nghiên cứu. Đây là điều quan trọng bởi vì khả năng của các ngân hàng trong việc thu hút khách hàng và giữ chân họ trên cơ sở lâu dài có liên quan mạnh mẽ đến lợi nhuận của họ (Keisidou, Sarigiannidis, Maditinos, \& Thalassinos, 2013).

\subsubsection{Khái niệm về sụ hài lòng}

Sự hài lòng của khách hàng trong việc xử lý khiếu nại là mức độ mà khách hàng cảm thấy hài lòng đối với những gì họ đề xuất với ngân hàng. Sự hài lòng của khách hàng cho thấy họ thỏa mãn với những gì ngân hàng đã thực hiện với họ thông qua các đề xuất của họ đối với ngân hàng (Omoregie et al., 2019). Do đó, Kotler và Armstrong (2004) xác định sự hài lòng là cảm giác vui thích hay thất vọng so với hiệu suất của một sản phẩm bị lừa dối (hoặc kết quả) và mong đợi của khách hàng. Sự hài lòng của khách hàng là cảm giác hạnh phúc hoặc không vui sau khi so sánh hiệu suất sản phẩm mà họ cảm nhận được so với sự kỳ đợi trước đó. Nếu hiệu suất sản phẩm được xem xét dưới mức mong đợi, điều đó có nghĩa là khách hàng không hài lòng; ngược lại, nếu hiệu suất được xem xét trên mức mong đợi có nghĩa là khách hàng hài lòng.

\subsubsection{Khái niệm về Giá trị nhận được}

Giá trị nhận được đề cập đến việc ngân hàng cung cấp các sản phẩm/dịch vụ với mức phí thấp hơn các ngân hàng khác hoặc với một mức phí cạnh tranh nhưng vẫn đảm bảo về chất lượng sản phẩm/dịch vụ tương tự các ngân hàng khác. Giá trị nhận được còn cho thấy những lợi ích mà khách hàng nhận được là xứng đáng với những gì họ đã bỏ ra từ vấn đề về tài chính, công sức và thời gian (Hapsari, Clemes, \& Dean, 2017; Yang \& Peterson, 2004). 


\subsection{Các giả thuyết nghiên cúu}

2.2.1. Mối quan hệ giũa Chất luợng dịch vu, Hình ảnh thưong hiệu, Niềm tin và Lòng trung thành của khách hàng cá nhân

Chất lượng sản phẩm và dịch vụ do ngân hàng cung cấp là một trong những tiêu chí được khách hàng sử dụng để xác định sự lựa chọn của ngân hàng. Một ngân hàng cung cấp dịch vụ chất lượng tốt là một yếu tố quyết định quan trọng đối với lòng trung thành của khách hàng. Đây là một nhận thức được tạo ra thông qua quá trình tương tác giữa khách hàng và nhân viên ngân hàng. Ofori, Boakye, và Narteh (2018) cho rằng chất lượng dịch vụ là yếu tố thúc đẩy sự hài lòng của khách hàng, từ đó tạo ra lòng trung thành của khách hàng. Không giống như thị trường hàng hóa nơi mà một sản phẩm vật chất có thể dễ dàng cảm nhận được, ngành ngân hàng cung cấp các dịch vụ mà chất lượng có thể khó đánh giá (Pleshko \& Heiens, 2015). Các nghiên cứu thực nghiệm đã chứng minh tác động của chất lượng dịch vụ cả đến sự hài lòng và lòng trung thành của khách hàng (Makanyeza \& Chikazhe, 2017; Ofori et al., 2018).

Stan, Caemmerer, và Cattan-Jallet (2013) cho rằng lòng trung thành của khách hàng đối với ngân hàng chịu tác động của nhiều yếu tố khác nhau bắt đầu từ nhận thức của khách hàng về chất lượng dịch vụ do ngân hàng cung cấp. Nhận thức về chất lượng dịch vụ có tác động mạnh mẽ đến nhận thức của khách hàng về hình ảnh của ngân hàng và chính điều này đã tác động rất mạnh đến nhận thức của khách hàng về chất lượng dịch vụ của ngân hàng, từ đó dẫn đến lòng trung thành của khách hàng.

Nếu khách hàng thấy được chất lượng dịch vụ của ngân hàng thỏa đáng, ấn tượng về năng lực và tính chuyên nghiệp của ngân hàng thì họ sẽ lưu ý ngân hàng trong tâm trí của họ. Ofori và cộng sự (2018) và Hasiri và Afghanistanpour (2016) đã cho thấy rằng chất lượng dịch vụ ảnh hưởng mạnh mẽ đến hình ảnh của tổ chức và niềm tin vào các tổ chức. Điều này cho thấy rằng các ngân hàng đã tạo ra giá trị cho dịch vụ được cung cấp và đã phát triển niềm tin trong tâm trí khách hàng khi họ luôn cung cấp dịch vụ có chất lượng tốt (Gao, Waechter, \& Bai, 2015; Tang \& Nguyen, 2013). Niềm tin được tạo ra với khách hàng sẽ dẫn đến một hình ảnh thương hiệu tốt, cuối cùng dẫn đến việc gia tăng lòng trung thành của khách hàng.

Rorio (2013) đề nghị các ngân hàng luôn cần phải lịch sự vì điều này tạo ra một ấn tượng rất tích cực trong tâm trí khách hàng về chất lượng dịch vụ ngân hàng, do đó cải thiện lòng trung thành của khách hàng. Tweneboah-Koduah và Farley (2015) cũng phát hiện ra rằng sự thể hiện kiến thức làm việc tốt về các sản phẩm và dịch vụ ngân hàng của nhân viên ngân hàng, sự lịch sự và khả năng truyền cảm hứng và sự tự tin trong việc cung cấp dịch vụ là động lực đáng kể để khách hàng đến với ngân hàng. Mumin, Nkegbe, và Kuunibe (2012) và Kranias và Bourlessa (2013) đã phát hiện ra rằng sự thuận tiện và gần gũi ảnh hưởng đến lòng trung thành, trong khi năng lực của nhân viên, độ tin cậy, phương tiện hữu hình và tính sáng tạo về sản phẩm ảnh hưởng đến chất lượng dịch vụ.

Các tài liệu cho thấy rằng có một mối quan hệ trực tiếp mạnh mẽ giữa chất lượng dịch vụ và lòng trung thành trong nhiều nghiên cứu (Hapsari et al., 2017; Janita \& Miranda, 2013). Các nghiên cứu khác nhau cũng đã đề xuất vai trò trung gian của niềm tin (Ofori et al., 2018), sự hài lòng (Águila-Obra, Padilla-Meléndez, \& Al-dweeri, 2013; Hartono \& Raharjo, 2015), hình ảnh của tổ chức (Lai, Griffin, \& Babin, 2009) và giá trị nhận được (Hapsari et al., 2017; Janita \& Miranda, 2013; Lai et al., 2009) giữa chất lượng dịch vụ và lòng trung thành của khách hàng. Bakar, Clemes, và Bicknell (2017) cho thấy được hình ảnh thương hiệu và giá trị nhận được là yếu tố chính ảnh hưởng đến ý định hành vi của khách hàng. Ý định hành vi như vậy có thể bao gồm mua sản phẩm, dịch vụ và lòng trung thành của khách hàng. 
Một nghiên cứu của Makanyeza và Chikazhe (2017) ở Zimbabwe cho thấy chất lượng dịch vụ, sự hài lòng và hình ảnh thương hiệu đều có tác động trực tiếp tích cực đến lòng trung thành. Ngoài ra, nghiên cứu cho thấy sự hài lòng và hình ảnh thương hiệu làm trung gian ảnh hưởng của chất lượng dịch vụ đến lòng trung thành. Tuy nhiên, Saleem, Zahra, và Yaseen (2017) nhận thấy rằng mối liên hệ giữa chất lượng dịch vụ và lòng trung thành không qua trung gian hình ảnh thương hiệu. Hơn nữa, Saleem và cộng sự (2017) đã phát hiện ra rằng chất lượng dịch vụ và niềm tin có liên quan trực tiếp đến lòng trung thành. Đồng thời, ảnh hưởng của chất lượng dịch vụ và niềm tin đối với lòng trung thành đã được tìm thấy qua trung gian của sự hài lòng của khách hàng (Saleem et al., 2017).

Căn cứ trên đó, tác giả đề xuất các giả thuyết sau đây thể hiện vai trò của chất lượng dịch vụ trong việc cải thiện lòng trung thành của khách hàng đối với ngân hàng:

Hla: Chất luợng dịch vu ảnh hưởng tích cực đến hình ảnh thương hiệu

H1b: Chất lượng dịch vụ ảnh hưởng tích cưc đến giá trị nhận được

\section{H1c: Chất lượng dịch vụ ảnh hưởng tích cực đến niềm tin}

\section{H1d: Chất lượng dịch vu ảnh hưởng tích cực đến lòng trung thành}

2.2.2. Mối quan hệ giũa Hình ảnh thwơng hiệu, Niềm tin, Sụ hài lòng và Lòng trung thành của khách hàng cá nhân

Hình ảnh thương hiệu là một khía cạnh trong việc tiếp thị đến bên ngoài, hình ảnh thương hiệu là kết quả của khách hàng trong việc thực hiện so sánh giữa các thuộc tính khác nhau của các tổ chức. Hình ảnh thương hiệu giúp khách hàng xác định được nhà cung cấp dịch vụ họ đã dùng và mức độ tin cậy vào tổ chức đó (Afsar, Rehman, Qureshi, \& Shahjehan, 2010). Theo ghi nhận của Tu, Wang, và Chang (2012) và Ofori và cộng sự (2018), hình ảnh thương hiệu là một dạng tài sản vô hình có thể dễ dàng nhận biết nhưng khó bắt chước. Stan và cộng sự (2013) đề xuất rằng hình ảnh thương hiệu có mối quan hệ chặt chẽ với lòng trung thành của khách hàng.

Do sự cạnh tranh khốc liệt trong lĩnh vực ngân hàng, một lượng lớn sản phẩm và dịch vụ đã được phát triển để đáp ứng nhu cầu của khách hàng. Mặc dù sự hài lòng của khách hàng được coi là yếu tố chính quyết định sự trung thành của khách hàng đối với ngân hàng, nhưng nó được phát hiện có liên quan chặt chẽ đến dịch vụ được cung cấp và hình ảnh của ngân hàng được khách hàng nhận thức (Mumin et al., 2012). Arshad, Zahra, và Draz (2016) thấy rằng hình ảnh thương hiệu bao gồm thành phần thực tế và thành phần cảm xúc. Thành phần thực tế được thể hiện thông qua kích thước hữu hình có thể được biết đến và xem xét; điều này giải thích, tại sao các ngân hàng đầu tư vào các tòa nhà hấp dẫn về mặt thẩm mỹ cho địa điểm kinh doanh của họ. Trong khi đó, thành phần cảm xúc được liên kết với các đặc điểm và trải nghiệm tâm lý của khách hàng và lập trường của họ đối với ngân hàng và từ đó tạo được niềm tin vững chắc trong tâm trí khách hàng. Vì vậy, để thu hút khách hàng trung thành và các khách hàng mới, các ngân hàng cần phát triển hình ảnh thương hiệu mạnh mẽ, giúp nâng cao trải nghiệm và nhận thức của khách hàng về sản phẩm và dịch vụ của họ. Điều này sẽ xây dựng niềm tin trong tâm trí của khách hàng.

Sự phụ thuộc lẫn nhau và mối liên hệ giữa hình ảnh, niềm tin, sự hài lòng và lòng trung thành đã được chứng minh thông qua nhiều nghiên cứu thực nghiệm. Arshad và cộng sự (2016) cho thấy rằng sự hài lòng của khách hàng chịu sự tác động tử hình ảnh thương hiệu, không những thế hình ảnh thương hiệu có ảnh hưởng đến niềm tin và niềm tin có ảnh hưởng đến lòng trung thành của khách hàng. Tu và cộng sự (2012) cũng cho rằng các tổ chức nên tạo ra hình ảnh thương hiệu tốt hơn sẽ gia tăng được sự hài lòng và lòng trung thành của khách hàng vì kết quả 
nghiên cứu thực hiện đã chỉ rõ rằng hình ảnh thương hiệu ảnh hưởng mạnh đến sự hài lòng của khách hàng và lòng trung thành của khách hàng và sự hài lòng của khách hàng ảnh hưởng mạnh đến lòng trung thành của khách hàng.

Trên cơ sở đó, tác giả đề xuất các giả thuyết sau:

H2a: Hình ảnh thuoơng hiệu ảnh hương tích cưcc đến niềm tin

H2b: Hình ảnh thuoong hiệu ảnh hương tích cực đến sụ hài lòng

H2c: Hình ảnh thuơng hiệu ảnh hưởng tích cục đến lòng trung thành

2.2.3. Mối quan hệ giũa Niềm tin, Sụ hài lòng và Lòng trung thành của khách hàng cá nhân

Niềm tin là nền tảng vững chắc trong việc gia tăng sự hài lòng và lòng trung thành của khách hàng (Schoorman, Mayer, \& Davis, 2007). Theo quan điểm của Schoorman và cộng sự (2007), niềm tin là sự phản ánh sự sẵn sàng của khách hàng sử dụng dịch vụ/sản phẩm đối với nhà cung cấp dịch vụ hoặc nhà cung cấp sản phẩm dựa trên những kỳ vọng tích cực về chất lượng sản phẩm hoặc dịch vụ được cung cấp. Điều quan trọng là các tổ chức phải liên hệ với khách hàng một cách thiện chí để thiết lập niềm tin với họ. Bằng cách đó, niềm tin sẽ đảm bảo sự gia tăng hài lòng của khách hàng và thúc đẩy lòng trung thành của khách hàng lên mức cao hơn. Ngoài ra, niềm tin được thiết lập từ khách hàng có thể là một cách tiếp thị chiến lược khác, nơi khách hàng giới thiệu thương hiệu mình đang sử dụng cho bạn bè và gia đình (Afsar et al., 2010).

Khách hàng tin tưởng vào ngân hàng có thể là cơ sở để sử dụng dịch vụ ngân hàng liên tục vì niềm tin là lý do khiến khách hàng xây dựng mối quan hệ lâu dài với ngân hàng (Ofori et al., 2018). Ngân hàng càng có thể chiếm được niềm tin của khách hàng thì sự hài lòng và lòng trung thành của khách hàng sẽ được đảm bảo, và không có hệ lụy việc khách hàng chuyển đồi sang các tổ chức khác. Adam, Ofori, Okoe, và Boateng (2018) cho thấy được mối quan hệ tích cực giữa chất lượng dịch vụ và lòng trung thành của khách hàng, niềm tin và lòng trung thành của khách hàng. Điều này phù hợp với những phát hiện của Hasan, Kiong, và Ainuddin (2014) cho rằng giá trị và niềm tin nhận được có xu hướng tạo ra lòng trung thành của khách hàng với các tác động trung gian của sự hài lòng của khách hàng. Leninkumar (2017) cũng đã cho thấy tác động đáng kể của niềm tin đối với sự hài lòng và lòng trung thành của khách hàng.

Trên cơ sở đó, tác giả đề xuất các giả thuyết sau:

H3a: Niềm tin tác động tích cực đến sụ hài lòng

\section{H3b: Niềm tin tác động tích cực đến lòng trung thành}

\subsubsection{Mối quan hệ giữa Giá trị nhận được và Sụ hài lòng của khách hàng cá nhân}

Để khách hàng sử dụng dịch vụ liên tục, họ phải nhận thấy một số giá trị từ sản phẩm hoặc dịch vụ mà họ đã và đang sử dụng từ nhà cung cấp dịch vụ. Herman (2014) lưu ý rằng trong một thị trường cạnh tranh như lĩnh vực ngân hàng bán lẻ, chi phí cho khách hàng tiếp tục sử dụng dịch vụ là giá phải trả cho sản phẩm hoặc dịch vụ. Để khách hàng nhận thức được giá trị, ví dụ, lợi ích từ việc sử dụng sản phẩm hoặc dịch vụ cao hơn giá cả họ chi ra.

Các ngân hàng nỗ lực cung cấp các sản phẩm và dịch vụ mà khách hàng sẽ mong muốn và coi trọng, là tiền đề để đảm bảo sự hài lòng của khách hàng, điều này sẽ dẫn đến lòng trung thành. Korda và Snoj (2010) lập luận rằng các giá trị nhận được bắt nguồn từ mối quan hệ, mối quan hệ càng cao thì mức giá trị nhận được càng cao. Tạo ra nhận thức của khách hàng về giá trị 
nhận được đối với nhà cung cấp dịch vụ là bản chất chính của tiếp thị vì ý định mua lại được thúc đẩy bởi các giá trị nhận được của khách hàng. Giá trị nhận được của khách hàng về ngân hàng càng cao như nhận thức về chất lượng dịch vụ, bảo mật và niềm tin của khách hàng, và giá trị nhận được tác động tích cực đến sự hài lòng của khách hàng, dẫn đến mức độ trung thành của khách hàng đối với ngân hàng (Hasan et al., 2014).

Hasan và cộng sự (2014) cho rằng giá trị nhận được là yếu tố chính trong việc thúc đẩy lòng trung thành của khách hàng thông qua sự hài lòng của khách hàng. Và Chen (2015) cho rằng giá trị mà khách hàng nhận được có ảnh hưởng đáng kể đến lòng trung thành của khách hàng và sự hài lòng đóng vai trò trung gian trong mối quan hệ giữa giá trị và lòng trung thành. Cùng với đó, Hasan và cộng sự (2014) cũng đề nghị khách hàng đánh giá giá trị nhận được từ dịch vụ được hưởng bằng cách so sánh tỷ lệ đầu vào kết quả của một nhà cung cấp dịch vụ với nhà cung cấp dịch vụ khác trong việc quyết định tạo ra nhiều giá trị hơn trên mỗi đơn vị đầu vào. Các nghiên cứu cụ thể về sự hài lòng về giá trị nhận được như Keshavarz và Jamshidi (2018) và Bakar và cộng sự (2017) đề xuất rằng có một mối quan hệ tích cực đáng kể giữa giá trị nhận được và sự hài lòng. Irfan, Shamsudin, và Hadi (2016) cũng cho thấy được giá trị nhận được tác động tích cực đến sự hài lòng của khách hàng. Tương tự với những phát hiện này, Lai và cộng sự (2009) và Sugiati, Thoyib, Hadiwidjoyo, và Setiawan (2013) đã chứng minh rằng giá trị nhận được có ảnh hưởng tích cực đáng kể đến sự hài lòng của khách hàng. Rasheed và Abadi (2014) cũng nhận thấy rằng giá trị nhận được có tác động tích cực đáng kể đến lòng trung thành của khách hàng.

Trên cơ sở đó, tác giả đề xuất giả thuyết sau:

\section{H4: Giá trị nhận được tác động tích cưc đến sụ hài lòng}

\subsubsection{Mối quan hệ giũa Sự hài lòng và Lòng trung thành của khách hàng cá nhân}

Các nghiên cứu đã chứng minh có nhiều yếu tố tác động đến lòng trung thành của khách hàng, trong đó sự hài lòng của khách hàng là một yếu tố quan trọng. Một khách hàng hài lòng có nhiều khả năng lặp lại mua hàng và trở thành người dùng thường xuyên của một thương hiệu sản phẩm hoặc dịch vụ cụ thể hơn so với những khách hàng có trải nghiệm không thỏa mãn (Pleshko \& Heiens, 2015). Các nghiên cứu của Pandey và Devasagayam (2012) và Lei và Jolibert (2012) cũng cho thấy được sự hài lòng của khách hàng tác động tích cực đến lòng trung thành của khách hàng. Khi mức độ hài lòng của khách hàng tăng lên, mối quan hệ giữa ngân hàng và khách hàng được cải thiện dẫn đến tăng lòng trung thành (Omoregie et al., 2019).

Mặc dù có mối liên hệ trực tiếp giữa sự hài lòng và lòng trung thành của khách hàng, các nghiên cứu cũng chỉ ra rằng một số khách hàng có thể không trung thành mặc dù hài lòng với sản phẩm hoặc dịch vụ từ một nhà cung cấp hoặc thương hiệu, vì trung thành với các thương hiệu khác và không muốn chuyển sang các thương hiệu khác (Fraering \& Minor, 2013). Ganiyu (2017) kết luận rằng sự hài lòng của khách hàng là vô cùng quan trọng trong việc xây dựng và nâng cao lòng trung thành của khách hàng và tăng lợi nhuận.

Phát hiện từ Tweneboah-Koduah và Farley (2015) cho thấy sự hài lòng của khách hàng là yếu tố quyết định hoặc tiền đề quan trọng đối với khách hàng trong việc tiếp tục quay trở lại sử dụng dịch vụ của ngân hàng. Tweneboah-Koduah và Farley (2015) cho thấy có mối quan hệ tích cực và có ý nghĩa giữa sự hài lòng của khách hàng và lòng trung thành của khách hàng vì khả năng các ngân hàng đảm bảo cho dịch vụ của họ là yếu tố chính quyết định sự hài lòng. Một số nhà nghiên cứu như Fraering và Minor (2013) cũng đã cho thấy được mối quan hệ tích cực giữa sự hài lòng và lòng trung thành của khách hàng. 
Trên cơ sở đó, tác giả đề xuất giả thuyết sau: H5. Sự hài lòng của khách hàng tác động tích cực đến lòng trung thành của khách hàng.

\section{Phương pháp nghiên cứu}

Các phương pháp nghiên cứu được sử dụng như sau:

\subsection{Phưong pháp định tính}

Dựa trên cơ sở lý thuyết và các nghiên cứu đi trước, tác giả tiến hành tổng hợp thang đo và thảo luận với 10 chuyên gia trong việc hoàn chỉnh thang đo và thống nhất mô hình nghiên cứu. Từ đó, tác giả hoàn thiện bảng câu hỏi và tiến hành thu thập dữ liệu.

\subsection{Phương pháp định luọng}

Dữ liệu được thu thập bằng khảo sát thông qua bảng câu hỏi được thiết kế sẵn gửi trực tiếp đến 327 khách hàng tại các Ngân hàng TMCP trên địa bàn Thành phố Đà Nẵng để phỏng vấn và nhận kết quả ngay. Các kỹ thuật phân tích cơ bản (thống kê, Cronbach's Alpha, EFA, CFA, SEM) được thực hiện bằng phần mềm SPSS 20 và AMOS 20 nhằm thể hiện được mối quan hệ giữa Chất lượng dịch vụ, Hình ảnh thương hiệu, Giá trị nhận được, Niềm tin, Sự hài lòng và Lòng trung thành của khách hàng cá nhân trong ngành ngân hàng.

\section{Bảng 1}

Các thang đo thuộc các nhân tố trong mô hình nghiên cứu

\begin{tabular}{|c|c|c|c|c|}
\hline STT & $\begin{array}{c}\text { Nhân } \\
\text { tố }\end{array}$ & Mã hóa & Biến/thang đo & Nguồn \\
\hline 1 & \multirow{4}{*}{$\begin{array}{l}\text { Giá trị } \\
\text { nhận } \\
\text { được }\end{array}$} & GD1 & $\begin{array}{l}\text { So với các ngân hàng khác, Ngân hàng Anh/Chị đang } \\
\text { giao dịch cung cấp sản phẩm/dịch vụ với mức phí hâpp } \\
\text { dẫn }\end{array}$ & \multirow{4}{*}{$\begin{array}{l}\text { Yang và } \\
\text { Peterson } \\
\text { (2004), } \\
\text { Hapsari và } \\
\text { cộng sự } \\
\text { (2017) } \\
\end{array}$} \\
\hline 2 & & GD2 & $\begin{array}{l}\text { Ngân hàng Anh/Chị đang giao dịch có mức phí cạnh } \\
\text { tranh cho các sản phẩ/dịch vụ tương tự tại các ngân } \\
\text { hàng khác }\end{array}$ & \\
\hline 3 & & GD3 & $\begin{array}{l}\text { Cùng một mức phí chi trả tại các ngân hàng khác, } \\
\text { Anh/Chị nhận được những lợi ích tốt hơn từ Ngân hàng } \\
\text { mình đang giao dịch }\end{array}$ & \\
\hline 4 & & GD4 & $\begin{array}{l}\text { So với những gì đã bỏ ra (bao gồm tài chính, thời gian, } \\
\text { công sức), Anh/Chị nhận được dịch vụ tôt nhất từ Ngân } \\
\text { hàng Anh/Chị đang giao dịch }\end{array}$ & \\
\hline 5 & \multirow{4}{*}{$\begin{array}{l}\text { Chất } \\
\text { lượng } \\
\text { dịch vụ }\end{array}$} & CL1 & $\begin{array}{l}\text { Ngân hàng Anh/Chị đang giao dịch có đội ngũ nhân } \\
\text { viên phục vụ khách hàng tốt }\end{array}$ & \multirow{4}{*}{$\begin{array}{l}\text { Kaura, } \\
\text { Prasad, và } \\
\text { Sharma } \\
(2014) \text {, } \\
\text { Kant, } \\
\text { Jaiswal, } \\
\text { và Mishra } \\
\text { (2017) }\end{array}$} \\
\hline 6 & & CL2 & $\begin{array}{l}\text { Dịch vụ ngân hàng điện tử của Ngân hàng Anh/Chị đang } \\
\text { giao dịch cung cấp cho Anh/Chị các thông tin chính xác }\end{array}$ & \\
\hline 7 & & CL3 & $\begin{array}{l}\text { Ngân hàng Anh/Chị đang giao dịch cho Anh/Chị biết lãi } \\
\text { suất hoặc phí dịch vụ chính xác }\end{array}$ & \\
\hline 8 & & CL4 & $\begin{array}{l}\text { Anh/Chị có thể truy cập tìm hiểu thông tin sản } \\
\text { phẩm/dịch vụ của Ngân hàng Anh/Chị đang giao dịch } \\
\text { thông qua nhiều cách khác nhau (trực tuyến, điện thoại, } \\
\text { trực tiếp, ATM) }\end{array}$ & \\
\hline
\end{tabular}




\begin{tabular}{|c|c|c|c|c|}
\hline STT & $\begin{array}{c}\text { Nhân } \\
\text { tố }\end{array}$ & Mã hóa & Biến/thang đo & Nguồn \\
\hline 9 & & CL5 & $\begin{array}{l}\text { Giờ hoạt động của Ngân hàng Anh/Chị đang giao dịch } \\
\text { thuận tiện đối với Anh/Chị }\end{array}$ & \\
\hline 10 & & CL6 & $\begin{array}{l}\text { Ngân hàng Anh/Chị đang giao dịch có quy trình xử lý } \\
\text { khiếu nại hiệu quả }\end{array}$ & \\
\hline 11 & & CL7 & $\begin{array}{l}\text { Các tài liệu liên quan đến dịch vụ (như tờ rơi, bảng } \\
\text { quảng cáo) tại Ngân hàng Anh/Chị đang giao dịch rất } \\
\text { hấp dẫn về trực quan }\end{array}$ & \\
\hline 12 & \multirow{3}{*}{$\begin{array}{c}\text { Sự hài } \\
\text { lòng }\end{array}$} & HL1 & $\begin{array}{l}\text { Anh/Chị cảm thấy rất hài lòng với các dịch vụ tại Ngân } \\
\text { hàng Anh/Chị đang giao dịch }\end{array}$ & \multirow{3}{*}{$\begin{array}{l}\text { Xu, Peak, } \\
\text { và } \\
\text { Prybutok } \\
(2015)\end{array}$} \\
\hline 13 & & HL2 & $\begin{array}{l}\text { Anh/Chị rất rất yêu thích các dịch vụ tại Ngân hàng } \\
\text { Anh/Chị đang giao dịch }\end{array}$ & \\
\hline 14 & & HL3 & $\begin{array}{l}\text { Nhìn chung, Anh/Chị đánh giá tốt các sản phẩm/dịch vụ } \\
\text { mà Ngân hàng Anh/Chị đang giao dịch cung cấp }\end{array}$ & \\
\hline 15 & \multirow{5}{*}{$\begin{array}{l}\text { Hình } \\
\text { ảnh } \\
\text { thương } \\
\text { hiệu }\end{array}$} & HA1 & $\begin{array}{l}\text { Ngân hàng Anh/Chị đang giao dịch có biểu ngữ, logo dễ } \\
\text { dàng nhận diện }\end{array}$ & \multirow{5}{*}{$\begin{array}{c} \\
\text { Aydin và } \\
\text { Ozer } \\
\text { (2005), } \\
\text { Bayol, } \\
\text { Foye, } \\
\text { Tellier, và } \\
\text { Tenenhaus } \\
\text { (2000) } \\
\end{array}$} \\
\hline 16 & & HA2 & $\begin{array}{l}\text { Ngân hàng Anh/Chị đang giao dịch có sự phát triển ổn } \\
\text { định và vững chắc }\end{array}$ & \\
\hline 17 & & HA3 & $\begin{array}{l}\text { Ngân hàng Anh/Chị đang giao dịch có những đóng góp } \\
\text { tích cực cho xã hội }\end{array}$ & \\
\hline 18 & & HA4 & $\begin{array}{l}\text { Ngân hàng Anh/Chị đang giao dịch có một hình ảnh tốt } \\
\text { đẹp trong mắt khách hàng }\end{array}$ & \\
\hline 19 & & HA5 & $\begin{array}{l}\text { Ngân hàng Anh/Chị đang giao dịch có những sản } \\
\text { phẩm/dịch vụ, các hoạt động sáng tạo và hướng tới } \\
\text { tương lai }\end{array}$ & \\
\hline 20 & \multirow{4}{*}{$\begin{array}{c}\text { Niềm } \\
\text { tin }\end{array}$} & NT1 & $\begin{array}{l}\text { Ngân hàng Anh/Chị đang giao dịch có năng lực phục vụ } \\
\text { khách hàng tốt }\end{array}$ & \multirow{4}{*}{$\begin{array}{l}\text { Chai, } \\
\text { Malhotra, } \\
\text { và Alpert } \\
\text { (2015) }\end{array}$} \\
\hline 21 & & NT2 & $\begin{array}{l}\text { Ngân hàng Anh/Chị đang giao dịch có quy trình bảo mật } \\
\text { thông tin khách hàng tốt }\end{array}$ & \\
\hline 22 & & NT3 & $\begin{array}{l}\text { Ngân hàng Anh/Chị đang giao dịch có thái độ nồng hậu } \\
\text { và chu đáo đối với khách hàng }\end{array}$ & \\
\hline 23 & & NT4 & $\begin{array}{l}\text { Ngân hàng Anh/Chị đang giao dịch sẵ sàng chia sẻ } \\
\text { những khó khăn gặp phải trong giao dịch của khách } \\
\text { hàng }\end{array}$ & \\
\hline 24 & \multirow{2}{*}{$\begin{array}{l}\text { Lòng } \\
\text { trung } \\
\text { thành }\end{array}$} & TT1 & $\begin{array}{l}\text { Anh/Chị sẽ tiếp tục sử dụng dịch vụ mà Ngân hàng đang } \\
\text { cung câp cho Anh/Chị trong tương lai }\end{array}$ & \multirow{2}{*}{$\begin{array}{l}\text { Chai và } \\
\text { cộng sự } \\
\text { (2015) }\end{array}$} \\
\hline 25 & & TT2 & $\begin{array}{l}\text { Anh/chị sẽ sử dụng nhiều sản phẩm/dịch vụ khác nữa từ } \\
\text { Ngân hàng Anh/Chị đang giao dịch }\end{array}$ & \\
\hline
\end{tabular}




\begin{tabular}{|c|c|c|c|c|}
\hline STT & $\begin{array}{c}\text { Nhân } \\
\text { tố }\end{array}$ & Mã hóa & \multicolumn{1}{c|}{ Biến/thang đo } & Nguồn \\
\hline 26 & & $\begin{array}{l}\text { TTT3 } \\
\text { Anh/Chị sẽ nói những điều tích cực về Ngân hàng } \\
\text { Anh/Chị đang giao dịch với người khác }\end{array}$ & \\
\hline 27 & & TT4 & $\begin{array}{l}\text { Anh/Chị sẽ giới thiệu Ngân hàng Anh/Chị đang giao } \\
\text { dịch cho những người khác }\end{array}$ & \\
\hline
\end{tabular}

Nguồn: Tác giả tổng hợp

Để đảm bảo tính tin cậy trong việc phân tích, tác giả tiến hành khảo sát 350 phiếu và thu về 327 phiếu hợp lệ, điều này đảm bảo cỡ mẫu phân tích lớn hơn cỡ mẫu tối thiểu (cỡ mẫu tối thiểu: 5 x $27=135$ quan sát) theo quy định là gấp 04 hoặc 05 lần số biến quan sát (Hoang \& Chu, 2008).

\section{Bảng 2}

Kết quả thống kê mô tả

\begin{tabular}{|c|c|c|c|}
\hline Biến & Nội dung & Số lượng (n) & Tỷ lệ (\%) \\
\hline \multirow{2}{*}{ Giới tính } & Nam & 186 & 56.9 \\
\hline & Nữ & 141 & 43.1 \\
\hline \multirow{3}{*}{ Trình độ học vấn } & Trung cấp, cao đẳng & 18 & 5.5 \\
\hline & Đại học & 182 & 55.7 \\
\hline & Sau đại học & 127 & 38.8 \\
\hline \multirow{4}{*}{ Độ tuổi } & Dưới 25 tuổi & 13 & 4.0 \\
\hline & Từ 25 đến 35 tuổi & 85 & 26.0 \\
\hline & Từ 36 đến 45 tuồi & 189 & 57.8 \\
\hline & Trên 45 tuổi & 40 & 12.2 \\
\hline \multirow{3}{*}{ Thu nhập } & Dưới 5 triệu VND/tháng & 35 & 10.7 \\
\hline & Từ 5 đến 10 triệu VND/tháng & 171 & 52.3 \\
\hline & Trên 10 triệu VND/tháng & 121 & 37.0 \\
\hline
\end{tabular}

Nguồn: Kết quả phân tích SPSS

Trong 327 cá nhân khảo sát có 141 Nữ chiếm tỷ lệ $43.1 \%$ và 186 Nam chiếm tỷ lệ $56.9 \%$; trình độ học vấn chủ yếu là đại học chiếm đến $55.7 \%$. Độ tuổi chủ yếu từ 36 đến 45 tuổi chiếm tỷ lệ $57.8 \%$. Thu nhập từ 05 đến 10 triệu $\mathrm{VND}$ /tháng chiếm tỷ lệ cao nhất với $52.3 \%$.

\section{Kết quả nghiên cứu}

Phân tích đánh giá độ tin cậy thang đo qua hệ số Cronbach's Alpha cho thấy, các nhân tố đều có hệ số Cronbach's Alpha lớn hơn 0.7 ; nhân tố Chất lượng dịch vụ có hệ số Cronbach's Alpha lớn nhất là 0.940 và nhân tố Sự hài lòng có hệ số Cronbach's Alpha nhỏ nhất là 0.729 . Xét về hệ số tương quan biến tổng của hai biến CL7 thuộc nhân tố Chất lượng dịch vụ và TT4 thuộc nhân tố Lòng trung thành nhỏ hơn 0.3 ; do đó, hai biến này bị loại khi phân tích; tất cả các biến khác còn lại ( 25 biến của 06 nhóm nhân tố) đều có hệ số tương quan biến tổng lớn hơn 0.3 . 


\section{Bảng 3}

Tổng hợp hệ số Cronbach’s Alpha

\begin{tabular}{|l|c|c|c|}
\hline \multicolumn{1}{|c|}{ Nhân tố } & Số biến ban đầu & Hệ số Cronbach's Alpha & Số biến hợp lệ \\
\hline Chất lượng dịch vụ & 7 & 0.940 & 6 (Loại CL7) \\
\hline Hình ảnh thương hiệu & 5 & 0.887 & 5 \\
\hline Giá trị nhận được & 4 & 0.827 & 4 \\
\hline Niềm tin & 4 & 0.831 & 4 \\
\hline Sự hài lòng & 3 & 0.729 & 3 \\
\hline Lòng trung thành & 4 & 0.866 & 3 (Loại TT4) \\
\hline
\end{tabular}

Nguồn: Kết quả phân tích SPSS

Toàn bộ 25 biến thuộc các nhân tố thỏa mãn điều kiện phân tích đánh giá độ tin cậy Cronbach's Alpha được đưa vào phân tích nhân tố khám phá (EFA). Nhiệm vụ của EFA nhằm khám phá cấu trúc của thang đo các nhân tố: CL (Chất lượng dịch vụ), HA (Hình ảnh thương hiệu), GD (Giá trị nhận được), NT (Niềm tin), HL (Sự hài lòng), TT (Lòng trung thành). Sau khi đảm bảo thực hiện đúng quy trình EFA, các nhân tố sẽ được kiểm định để làm sạch dữ liệu.

\section{Bảng 4}

Kết quả phân tích nhân tố EFA

\begin{tabular}{|c|l|c|}
\hline \multicolumn{2}{|c|}{ Giá trị KMO } & 0.719 \\
\hline \multirow{2}{*}{ Kiểm định Bartlett's } & Giá trị Chi-Square & $7,198.595$ \\
\hline & df & 300 \\
\hline & Sig. & 0.000 \\
\hline
\end{tabular}

Nguồn: Kết quả phân tích SPSS

Kết quả phân tích EFA cho thấy hệ số KMO là 0.719 lớn hơn 0.5 với kiểm định Bartlett có giá trị $7,198.595$ có hệ số Sig. $=0.000$ nhỏ hơn 0.05 . Điều đó khẳng định kết quả phân tích EFA hoàn toàn có thể tin cậy.

\section{Bảng 5}

Kết quả xoay nhân tố

\begin{tabular}{|c|c|c|c|c|c|c|}
\hline & \multicolumn{9}{|c|}{ Thành phần } \\
\hline & $\mathbf{1}$ & $\mathbf{2}$ & $\mathbf{3}$ & $\mathbf{4}$ & $\mathbf{5}$ & $\mathbf{6}$ \\
\hline CL6 & 0.924 & & & & & \\
\hline CL3 & & & & & & \\
\hline CL1 & 0.923 & & & & \\
\hline CL4 & 0.878 & & & & \\
\hline CL2 & 0.842 & & & & \\
\hline CL5 & 0.822 & & & & \\
\hline
\end{tabular}




\begin{tabular}{|c|c|c|c|c|c|c|}
\hline & \multicolumn{6}{|c|}{ Thành phần } \\
\hline & 1 & 2 & 3 & 4 & 5 & 6 \\
\hline HA2 & & 0.935 & & & & \\
\hline HA5 & & 0.928 & & & & \\
\hline HA3 & & 0.799 & & & & \\
\hline HA1 & & 0.737 & & & & \\
\hline HA4 & & 0.658 & & & & \\
\hline GD3 & & & 0.905 & & & \\
\hline GD2 & & & 0.821 & & & \\
\hline GD4 & & & 0.778 & & & \\
\hline GD1 & & & 0.743 & & & \\
\hline NT3 & & & & 0.886 & & \\
\hline NT2 & & & & 0.835 & & \\
\hline NT4 & & & & 0.807 & & \\
\hline NT1 & & & & 0.732 & & \\
\hline TT3 & & & & & 0.900 & \\
\hline $\mathrm{TT} 2$ & & & & & 0.892 & \\
\hline TT1 & & & & & 0.863 & \\
\hline HL2 & & & & & & 0.858 \\
\hline HL1 & & & & & & 0.837 \\
\hline HL3 & & & & & & 0.707 \\
\hline Giá trị riêng & 6.436 & 3.245 & 2.799 & 2.117 & 1.759 & 1.657 \\
\hline Phương sai trích (\%) & 25.743 & 12.980 & 11.195 & 8.467 & 7.036 & 6.626 \\
\hline Phương sai trích tích lũy (\%) & 25.743 & 38.723 & 49.918 & 58.384 & 65.421 & 72.047 \\
\hline
\end{tabular}

Nguồn: Kết quả phân tích SPSS

Đồng thời, phân tích phương sai trích cho thấy, phương sai trích đạt giá trị $72.047 \%$. Giá trị này khá cao với $72.047 \%$ biến thiên của dữ liệu được giải thích bởi sáu nhân tố. Các thang đo được rút ra và chấp nhận, điểm dừng khi trích các nhân tố tại nhân tố thứ sáu với giá trị riêng là 1.657 lớn hơn 1 (điều này khẳng định các biến đưa vào được sắp xếp thành sáu nhóm nhân tố). Cùng với đó, kết quả phép xoay nhân tố cho thấy được các hệ số đều thỏa mãn yêu cầu (các giá trị hệ số tải nhân tố đều lớn hơn 0.5 ) và sắp xếp theo sáu nhóm nhân tố riêng biệt, đó là các nhóm nhân tố CL (Chất lượng dịch vụ), HA (Hình ảnh thương hiệu), GD (Giá trị nhận được), NT (Niềm tin), HL (Sự hài lòng), TT (Lòng trung thành). 


\section{Bảng 6}

Các chỉ tiêu đánh giá kết quả phân tích CFA theo hệ số chuẩn hóa

\begin{tabular}{|c|l|c|}
\hline $\mathbf{S T T}$ & \multicolumn{1}{|c|}{ Chỉ tiêu } & Giá trị \\
\hline $\mathbf{1}$ & Chi-square/df & 2.280 \\
\hline $\mathbf{2}$ & P-value của Chi-square & 0.000 \\
\hline $\mathbf{3}$ & GFI & 0.881 \\
\hline $\mathbf{4}$ & TLI & 0.946 \\
\hline $\mathbf{5}$ & CFI & 0.954 \\
\hline $\mathbf{6}$ & RMSEA & 0.063 \\
\hline
\end{tabular}

Nguồn: Kết quả phân tích AMOS

Tiếp theo, kết quả phân tích CFA cho thấy, giá trị Chi-square/df $=2.280$ nhỏ hơn 3 , $\mathrm{GFI}=0.881$ lớn hơn $0.8 ; \mathrm{TLI}=0.946$ lớn hơn $0.9 ; \mathrm{CFI}=0.954$ lớn hơn 0.95 và $\mathrm{RMSEA}=$ 0.063 nhỏ hơn 0.08 ; do đó, có thể nói mô hình phù hợp với dữ liệu thị trường. Đồng thời, các trọng số chuẩn hóa đều lớn hơn 0.5. Điều đó có ý nghĩa thống kê nên các khái niệm đạt được giá trị hội tụ. Vì vậy, các nhân tố chính được đưa vào phân tích, đó là: CL (Chất lượng dịch vụ), HA (Hình ảnh thương hiệu), GD (Giá trị nhận được), NT (Niềm tin), HL (Sự hài lòng), TT (Lòng trung thành).

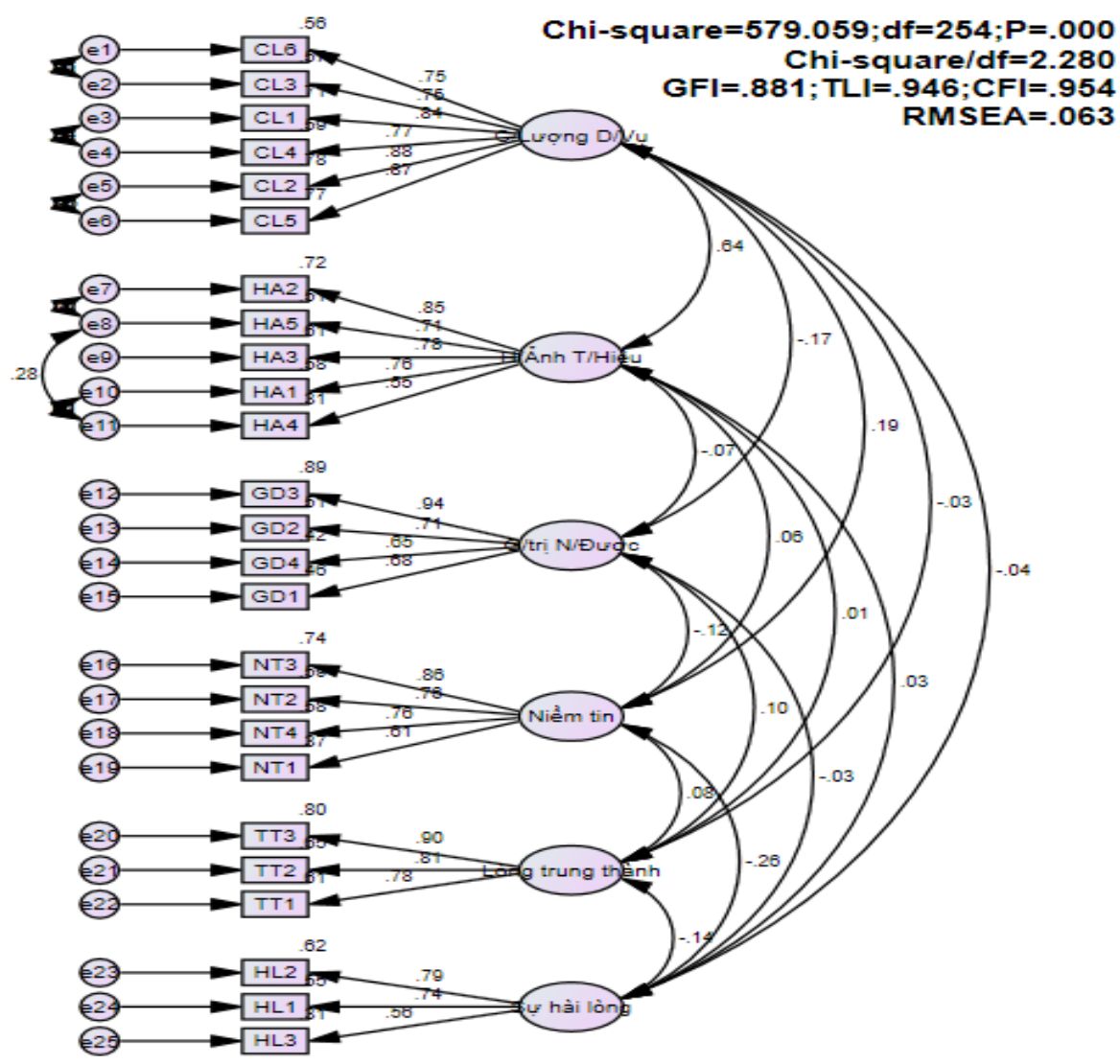

Hình 1. Kết quả phân tích CFA theo hệ số chuẩn hóa của các nhân tố Nguồn: Kết quả phân tích AMOS 


\section{Bảng 7}

Tổng hợp giá trị độ tin cậy tổng hợp và tổng phương sai trích các nhân tố

\begin{tabular}{|c|c|c|c|}
\hline STT & Nhân tố & Độ tin cậy tổng hộp & Tổng phương sai trích \\
\hline 1 & Chất lượng dịch vụ & 0.902 & 0.701 \\
\hline 2 & Hình ảnh thương hiệu & 0.859 & 0.654 \\
\hline 3 & Giá trị nhận được & 0.817 & 0.605 \\
\hline 4 & Niềm tin & 0.816 & 0.646 \\
\hline 5 & Sự hài lòng & 0.851 & 0.657 \\
\hline 6 & Lòng trung thành & 0.771 & 0.612 \\
\hline
\end{tabular}

Nguồn: Kết quả tính toán của tác giả

Cùng với đó, kết quả phân tích cho thấy, các giá trị độ tin cậy tổng hợp lớn hơn 0.7 và tổng phương sai trích của các nhân tố đều lớn hơn 0.5 . Điều này cho thấy các nhân tố đảm bảo độ tin cậy khi đưa vào phân tích. Và giá trị $\mathrm{P}$-value của các hệ số tương quan từng cặp đều nhỏ hơn 0.05 (tức nhỏ hơn 5\%), nên hệ số tương quan từng cặp của các khái niệm khác biệt so với 1 ở độ tin cậy $95 \%$. Do đó, các khái niệm đạt được giá trị phân biệt.

\section{Bảng 8}

Các chỉ tiêu đánh giá kết quả phân tích mô hình SEM theo hệ số chuẩn hóa

\begin{tabular}{|c|l|c|}
\hline $\mathbf{1}$ & \multicolumn{1}{|c|}{ Chỉ tiêu } & Giá trị \\
\hline $\mathbf{1}$ & Chi-square/df & 2.262 \\
\hline $\mathbf{2}$ & P-value của Chi-square & 0.000 \\
\hline $\mathbf{3}$ & GFI & 0.880 \\
\hline $\mathbf{4}$ & TLI & 0.947 \\
\hline $\mathbf{5}$ & CFI & 0.954 \\
\hline $\mathbf{6}$ & RMSEA & 0.062 \\
\hline
\end{tabular}

Nguồn: Kết quả phân tích AMOS

Kế thừa từ kết quả phân tích $\mathrm{CFA}$, kết quả của mô hình cấu trúc tuyến tính SEM cũng phù hợp với dữ liệu thị trường. Điều đó thể hiện qua các chỉ số như: giá trị Chi-square/df = 2.262 nhỏ hơn $3, \mathrm{GFI}=0.880$ lớn hơn $0.8 ; \mathrm{TLI}=0.947$ lớn hơn $0.9 ; \mathrm{CFI}=0.954$ lớn hơn 0.95 và $\mathrm{RMSEA}=0.062$ nhỏ hơn 0.08 . 


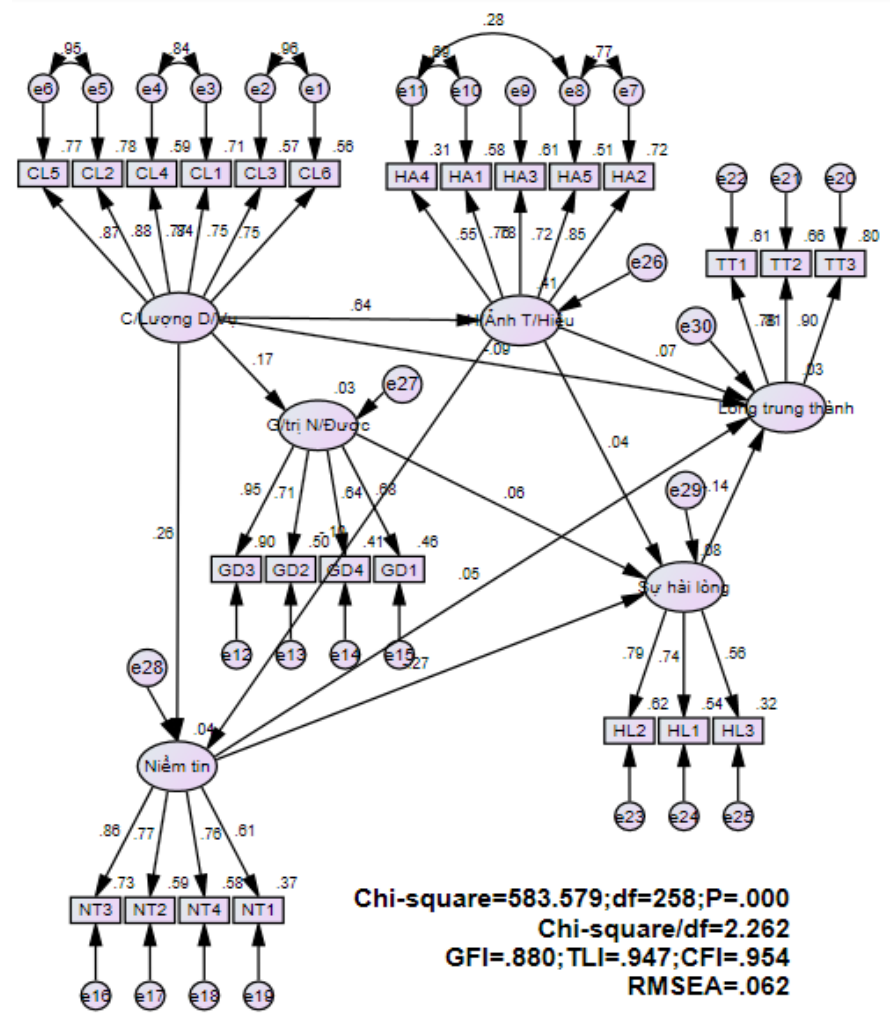

Hình 2. Kết quả mô hình cấu trúc tuyến tính SEM thể hiện tác động của các nhân tố Nguồn: Kết quả phân tích AMOS

\section{Bảng 9}

Kết quả mô hình SEM

\begin{tabular}{|c|c|c|c|c|c|c|}
\hline \multicolumn{3}{|c|}{ Mối quan hệ } & Hệ số hồi quy & S.E. & C.R. & $\mathbf{P}$ \\
\hline Hình ảnh thương hiệu & $<--$ & Chất lượng dịch vụ & 0.694 & 0.071 & 9.832 & $* * *$ \\
\hline Giá trị nhận được & $<--$ & Chất lượng dịch vụ & 0.197 & 0.070 & 2.813 & 0.005 \\
\hline Niềm tin & $<--$ & Chất lượng dịch vụ & 0.293 & 0.102 & 2.866 & 0.004 \\
\hline Niềm tin & $<--$ & $\begin{array}{l}\text { Hình ảnh thương } \\
\text { hiệu }\end{array}$ & 0.108 & 0.095 & 1.137 & 0.005 \\
\hline Sự hài lòng & $<--$ & $\begin{array}{l}\text { Hình ảnh thương } \\
\text { hiệu }\end{array}$ & 0.032 & 0.060 & 0.540 & 0.005 \\
\hline Sự hài lòng & $<--$ & Niềm tin & 0.233 & 0.059 & 3.970 & $* * *$ \\
\hline Sự hài lòng & $<--$ & Giá trị nhận được & 0.048 & 0.054 & 0.879 & 0.010 \\
\hline Lòng trung thành & $<--$ & Chất lượng dịch vụ & 0.103 & 0.101 & 1.019 & 0.008 \\
\hline Lòng trung thành & $<--$ & $\begin{array}{l}\text { Hình ảnh thương } \\
\text { hiệu }\end{array}$ & 0.069 & 0.093 & 0.740 & 0.009 \\
\hline Lòng trung thành & $<--$ & Niềm tin & 0.054 & 0.067 & 0.803 & 0.002 \\
\hline Lòng trung thành & $<--$ & Sự hài lòng & 0.157 & 0.082 & 1.917 & 0.005 \\
\hline
\end{tabular}

***: Tức $0.000(0 \%)$

Nguồn: Kết quả phân tích AMOS 
Đồng thời, căn cứ trên kết quả phân tích, giá trị P-value của các mối quan hệ tác động giữa các nhân tố, ta thấy, giá trị P-value đều nhỏ hơn $5 \%$. Do đó, mối quan hệ giữa các nhân tố CL (Chất lượng dịch vụ), HA (Hình ảnh thương hiệu), GD (Giá trị nhận được), NT (Niềm tin), HL (Sự hài lòng), TT (Lòng trung thành) đều có ý nghĩa thống kê trong mô hình cấu trúc tuyến tính SEM.

\section{Bảng 10}

Kết quả mô hình SEM theo hệ số chuẩn hóa

\begin{tabular}{|l|l|l|c|c|}
\hline \multicolumn{2}{|c|}{ Mối quan hệ } & Hệ số hồi quy & Hệ số làm tròn theo so đồ \\
\hline Hình ảnh thương hiệu & $<---$ & Chất lượng dịch vụ & 0.642 & $\mathbf{0 . 6 4}$ \\
\hline Giá trị nhận được & $<--$ & Chất lượng dịch vụ & 0.172 & $\mathbf{0 . 1 7}$ \\
\hline Niềm tin & $<--$ & Chất lượng dịch vụ & 0.260 & $\mathbf{0 . 2 6}$ \\
\hline Niềm tin & $<---$ & Hình ảnh thương hiệu & 0.103 & $\mathbf{0 . 1 0}$ \\
\hline Sự hài lòng & $<---$ & Hình ảnh thương hiệu & 0.036 & $\mathbf{0 . 0 4}$ \\
\hline Sự hài lòng & $<---$ & Niềm tin & 0.273 & $\mathbf{0 . 2 7}$ \\
\hline Sự hài lòng & $<--$ & Giá trị nhận được & 0.057 & $\mathbf{0 . 0 6}$ \\
\hline Lòng trung thành & $<---$ & Chất lượng dịch vụ & 0.093 & $\mathbf{0 . 0 9}$ \\
\hline Lòng trung thành & $<---$ & Hình ảnh thương hiệu & 0.067 & $\mathbf{0 . 0 7}$ \\
\hline Lòng trung thành & $<---$ & Niềm tin & 0.055 & $\mathbf{0 . 0 5}$ \\
\hline Lòng trung thành & $<---$ & Sự hài lòng & 0.136 & $\mathbf{0 . 1 4}$ \\
\hline
\end{tabular}

Nguồn: Kết quả phân tích AMOS

Khi xem xét giá trị hệ số hồi quy giữa các nhân tố cho thấy giá trị hệ số hồi quy đều lớn hơn 0 , tức tồn tại sự tác động tích cực giữa các nhân tố với nhau, cụ thể như sau:

Nhân tố CL (Chất lượng dịch vụ) tác động tích cực đến HA (Hình ảnh thương hiệu), GD (Giá trị nhận được), NT (Niềm tin) với hệ số hồi quy lần lượt là $0.64 ; 0.17 ; 0.26$; điều này có nghĩa rằng, khi nhân tố $\mathrm{CL}$ (Chất lượng dịch vụ) gia tăng/tốt hơn thì HA (Hình ảnh thương hiệu), GD (Giá trị nhận được), NT (Niềm tin) sẽ gia tăng (với mức tăng thêm tương ứng một lần CL (Chất lượng dịch vụ) thì HA (Hình ảnh thương hiệu), GD (Giá trị nhận được), NT (Niềm tin) tăng thêm lần lượt là 0.64 lần; 0.17 lần và 0.26 lần).

Nhân tố HA (Hình ảnh thương hiệu) tác động tích cực đến NT (Niềm tin), HL (Sự hài lòng) với hệ số hồi quy lần lượt là 0.10 và 0.04 ; điều này có nghĩa rằng, khi nhân tố $\mathrm{HA}$ (Hình ảnh thương hiệu) gia tăng/tốt hơn thì NT (Niềm tin), HL (Sự hài lòng) sẽ gia tăng (với mức tăng thêm tương ứng một lần HA (Hình ảnh thương hiệu) thì NT (Niềm tin), HL (Sự hài lòng) tăng thêm lần lượt là 0.10 lần và 0.04 lần).

Nhân tố NT (Niềm tin), GD (Giá trị nhận được) tác động tích cực đến HL (Sự hài lòng) với hệ số hồi quy lần lượt là 0.27 và 0.06 ; điều này có nghĩa rằng, khi nhân tố $\mathrm{NT}$ (Niềm tin), GD (Giá trị nhận được) gia tăng/tốt hơn thì HL (Sự hài lòng) sẽ gia tăng (với mức tăng thêm tương ứng một lần NT (Niềm tin), GD (Giá trị nhận được) thì HL (Sự hài lòng) tăng thêm lần lượt là 0.27 lần và 0.06 lần).

Và cuối cùng, nhân tố CL (Chất lượng dịch vụ), HA (Hình ảnh thương hiệu), NT (Niềm tin), HL (Sự hài lòng) tác động tích cực đến TT (Lòng trung thành) với hệ số hồi quy là 0.09 ; $0.07 ; 0.05 ; 0.14$. Điều này có nghĩa là, khi nhân tố CL (Chất lượng dịch vụ), HA (Hình ảnh thương hiệu), NT (Niềm tin), HL (Sự hài lòng) tốt hơn thì TT (Lòng trung thành) sẽ gia tăng (với 
mức tăng thêm tương ứng một lần CL (Chất lượng dịch vụ), HA (Hình ảnh thương hiệu), NT (Niềm tin), HL (Sự hài lòng) thì TT (Lòng trung thành) tăng thêm 0.09 lần; 0.07 lần; 0.05 lần và 0.14 lần).

Tiếp theo tác giả tiến hành kiểm định Bootstrap và thu được kết quả cụ thể như sau:

\section{Bảng 11}

Kết quả kiểm định Bootstrap

\begin{tabular}{|l|c|l|c|c|c|c|}
\hline \multicolumn{2}{|c|}{ Mối quan hệ } & Hệ số hồi quy & Bias & SE-Bias Giá trị CR \\
\hline Hình ảnh thương hiệu & $<--$ & Chất lượng dịch vụ & 0.642 & 0.006 & 0.004 & $\mathbf{1 . 5 0}$ \\
\hline Giá trị nhận được & $<---$ & Chất lượng dịch vụ & 0.172 & 0.001 & 0.003 & $\mathbf{0 . 3 3}$ \\
\hline Niềm tin & $<---$ & Chất lượng dịch vụ & 0.260 & 0.008 & 0.006 & $\mathbf{1 . 3 3}$ \\
\hline Niềm tin & $<---$ & Hình ảnh thương hiệu & 0.103 & 0.002 & 0.003 & $\mathbf{0 . 6 7}$ \\
\hline Sự hài lòng & $<---$ & Hình ảnh thương hiệu & 0.036 & 0.004 & 0.004 & $\mathbf{1 . 0 0}$ \\
\hline Sự hài lòng & $<---$ & Niềm tin & 0.273 & 0.008 & 0.006 & $\mathbf{1 . 3 3}$ \\
\hline Sự hài lòng & $<--$ & Giá trị nhận được & 0.057 & 0.009 & 0.008 & $\mathbf{1 . 1 3}$ \\
\hline Lòng trung thành & $<---$ & Chất lượng dịch vụ & 0.093 & 0.000 & 0.004 & $\mathbf{0 . 0 0}$ \\
\hline Lòng trung thành & $<---$ & Hình ảnh thương hiệu & 0.067 & 0.000 & 0.003 & $\mathbf{0 . 0 0}$ \\
\hline Lòng trung thành & $<---$ & Niềm tin & 0.055 & 0.001 & 0.004 & $\mathbf{0 . 2 5}$ \\
\hline Lòng trung thành & $<---$ & Sự hài lòng & 0.136 & 0.004 & 0.003 & $\mathbf{1 . 3 3}$ \\
\hline
\end{tabular}

Nguồn: Kết quả phân tích AMOS

Căn cứ trên kết quả kiểm định Bootstrap cho thấy giá trị tuyệt đối của CR nhỏ hơn so với 2 nên có thể kết luận rằng độ lệch chuẩn là rất nhỏ, điều đó cho thấy kết quả mô hình hồi quy tuyến tính SEM có thể tin cậy được.

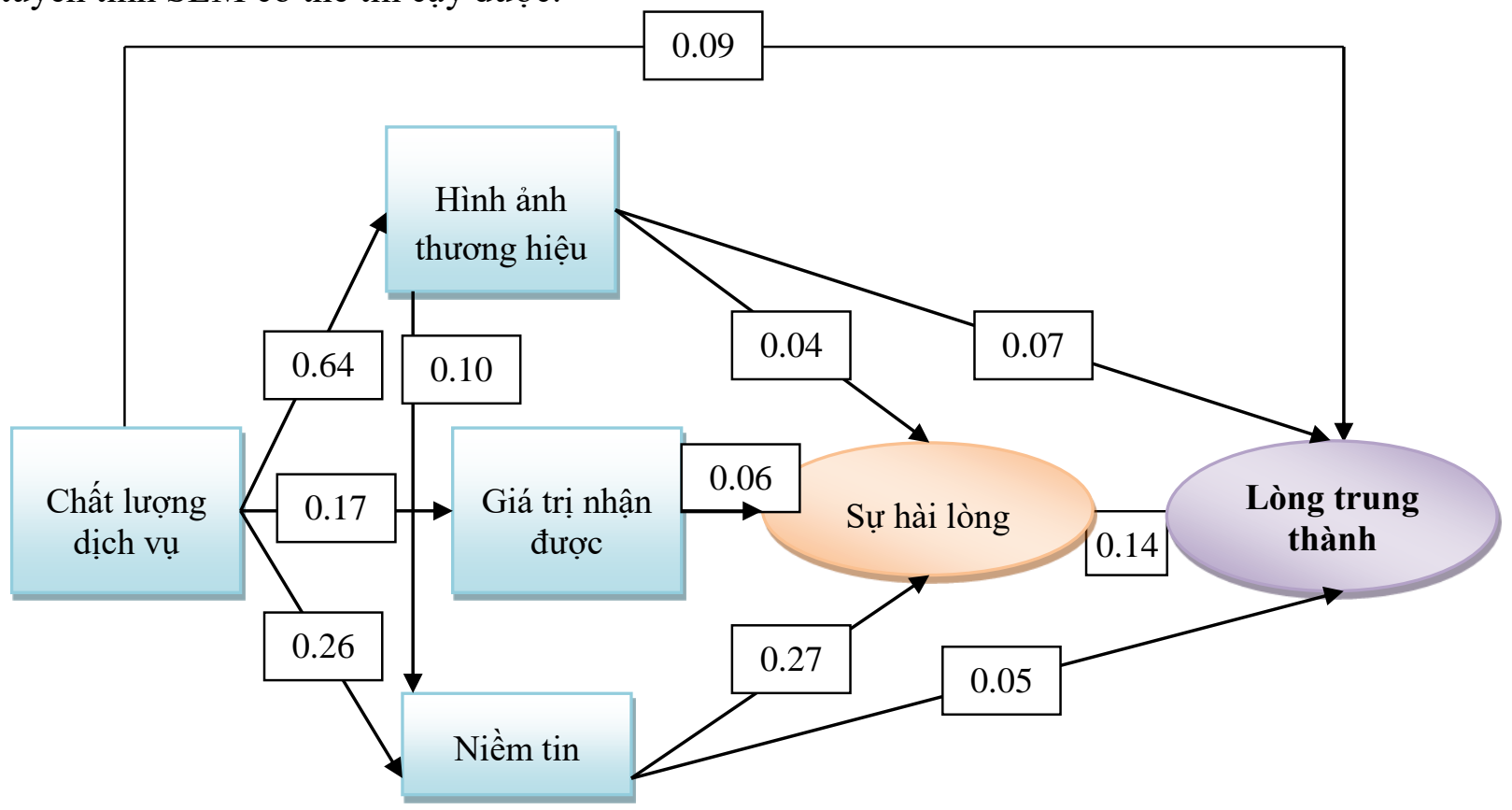

Hình 3. Kết quả mô hình cấu trúc tuyến tính SEM thể hiện mối quan hệ giữa các nhân tố Chất lượng dịch vụ, Hình ảnh thương hiệu, Giá trị nhận được, Niềm tin, Sự hài lòng và Lòng trung thành Nguồn: Kết quả phân tích của tác giả 
Như vậy, sau khi thực hiện phân tích mô hình cấu trúc tuyến tính SEM, nghiên cứu đã cho thấy được mối quan hệ giữa các nhân tố Chất lượng dịch vụ, Hình ảnh thương hiệu, Giá trị nhận được, Niềm tin, Sự hài lòng và Lòng trung thành của khách hàng cá nhân trong ngành ngân hàng, cụ thể: (1) Nhân tố CL (Chất lượng dịch vụ) tác động tích cực đến HA (Hình ảnh thương hiệu), GD (Giá trị nhận được), NT (Niềm tin); (2) Nhân tố HA (Hình ảnh thương hiệu) tác động tích cực đến NT (Niềm tin), HL (Sự hài lòng); (3) Nhân tố NT (Niềm tin), GD (Giá trị nhận được) tác động tích cực đến HL (Sự hài lòng) và (4) Nhân tố CL (Chất lượng dịch vụ), HA (Hình ảnh thương hiệu), NT (Niềm tin), HL (Sự hài lòng) tác động tích cực đến TT (Lòng trung thành).

\section{Kết luận và hàm ý quản trị}

\subsection{Kết luận}

Dựa trên nền tảng các lý thuyết liên quan đến Chất lượng dịch vụ, Hình ảnh thương hiệu, Giá trị nhận được, Niềm tin, Sự hài lòng và Lòng trung thành, các nghiên cứu đi trước liên quan đến chủ đề nghiên cứu, tác giả đã tiến hành xây dựng thang đo và mô hình nghiên cứu đề xuất với 6 nhân tố chính bao gồm: CL (Chất lượng dịch vụ), HA (Hình ảnh thương hiệu), GD (Giá trị nhận được), NT (Niềm tin), HL (Sự hài lòng), TT (Lòng trung thành). Tiếp theo, tác giả tiến hành nghiên cứu định tính để hiệu chỉnh và bổ sung các sai sót nếu có, sau đó tiến hành lập bảng khảo sát và tiến hành khảo sát chính thức để thu thập ý kiến của các cá nhân là khách hàng có phát sinh giao dịch với các Ngân hàng thương mại trên địa bàn Thành phố Đà Nẵng. Với cơ sở dữ liệu thu thập được, tác giả tiến hành ứng dụng phần mềm SPSS 20, AMOS 20 để phân tích; nghiên cứu đã đạt được các kết quả nhất định như sau:

- Nghiên cứu cho thấy được các khái niệm cơ bản nhất và các thang đo để đo lường các nhân tố CL (Chất lượng dịch vụ), HA (Hình ảnh thương hiệu), GD (Giá trị nhận được), NT (Niềm tin), HL (Sự hài lòng), TT (Lòng trung thành); các kết quả nghiên cứu đi trước cho thấy được mối quan hệ cũng như sự tác động của các nhân tố lẫn nhau thông quan các giả thuyết nghiên cứu làm cơ sở khoa học cho các nghiên cứu theo sau;

- Tiếp theo, nghiên cứu đã thực hiện thống kê sơ bộ các thông tin về các đối tượng khảo sát như: giới tính, trình độ học vấn, độ tuổi và thu nhập;

- Cùng với đó, kết quả đánh giá độ tin cậy thang đo thông qua kỹ thuật phân tích Cronbach's Alpha cho thấy với 27 biến (bao gồm các biến của các nhân tố) đều đạt yêu cầu đánh giá, các hệ số Cronbach's Alpha từ 0.7 trở lên và hệ số tương quan biến tổng các biến đều lớn hơn 0.3 ngoại trừ biến CL7 (thuộc nhân tố Chất lượng dịch vụ) và TT4 (thuộc nhân tố Lòng trung thành) với hệ số tương quan biến tổng nhỏ hơn 0.3 và kết quả phân tích nhân tố khám phá EFA cho thấy tất cả các biến thuộc các nhân tố đều đạt yêu cầu phân tích (các giá trị hệ số tải nhân tố đều lớn hơn 0.5 ); với tổng số biến là 25 biến và được sắp xếp theo 06 nhóm nhân tố, đó là CL (Chất lượng dịch vụ), HA (Hình ảnh thương hiệu), GD (Giá trị nhận được), NT (Niềm tin), HL (Sự hài lòng), TT (Lòng trung thành);

- Đặc biệt, kết quả phân tích nhân tố khẳng định CFA cho thấy mô hình phù hợp với dữ liệu thị trường, các thang đo đảm bảo độ tin cậy, các khái niệm đạt được giá trị phân biệt và mô hình cấu trúc tuyến tính SEM cho thấy: (1) Nhân tố CL (Chất lượng dịch vụ) tác động tích cực đến HA (Hình ảnh thương hiệu), GD (Giá trị nhận được), NT (Niềm tin); (2) Nhân tố HA (Hình ảnh thương hiệu) tác động tích cực đến NT (Niềm tin), HL (Sự hài lòng); (3) Nhân tố NT (Niềm tin), GD (Giá trị nhận được) tác động tích cực đến HL (Sự hài lòng) và (4) Nhân tố CL (Chất lượng dịch vụ), HA (Hình ảnh thương hiệu), NT (Niềm tin), HL (Sự hài lòng) tác động tích cực đến TT (Lòng trung thành). 


\subsection{Hàm ý quản trị}

Dựa trên kết quả từ mô hình, để gia tăng Sự hài lòng và Lòng trung thành của khách hàng trong ngành ngân hàng, nghiên cứu đề xuất một số hàm ý như sau:

- Nâng cao chất lượng phục vụ khách hàng thông qua các hoạt động như: Thực hiện việc nghiên cứu và tìm hiểu các dịch vụ hay và thực tế, phù hợp với nhu cầu của khách hàng nhằm đa dạng hóa các sản phẩm/dịch vụ mà các Ngân hàng thương mại hiện nay đang cung cấp; cần thiết phải thực hiện các cuộc khảo sát, lấy ý kiến của khách hàng cũng như tổ chức các buổi hội nghị, hội thảo nhằm thu thập các ý kiến, các nhu cầu của khách hàng về các sản phẩm/dịch vụ mà họ mong muốn được sử dụng;

- Đảm bảo việc cung cấp thông tin chính xác cho khách hàng, để thực hiện điều này, các Ngân hàng thương mại nên: Thực hiện đúng các quy trình cung cấp dịch vụ cho khách hàng; thực hiện công tác quản lý sản phẩm/dịch vụ, các thủ tục hồ sơ theo tiêu chuẩn quản lý chất lượng ISO nhằm đem đến tính hiệu quả và chất lượng trong việc quản lý các sản phẩm, dịch vụ cũng như thủ tục giấy tờ;

- Bên cạnh đó, các Ngân hàng thương mại cần phải thực hiện các chương trình quảng cáo ngoài trời như đạp xe quanh tỉnh thành trên các con đường lớn với khẩu hiệu và logo của mình để khách hàng dễ nhận biết;

- Đề cao và khuyến khích các nhân viên đề xuất các ý tưởng trong việc cải tiến quy trình làm việc, cách thức làm việc mới mang tính khoa học và nâng cao hiệu suất công việc để giải quyết công việc một cách tốt nhất;

- Nâng cao năng lực phục vụ của nhân viên đối với khách hàng thông qua việc gia tăng kiến thức và kinh nghiệm nghề nghiệp cho nhân viên thông qua hoạt động đào tạo;

- Gia tăng thái độ phục vụ và giảm thiểu các khó khăn của khách hàng trong các hoạt động giao dịch tại các Ngân hàng thương mại.

Mặc dù cố gắng hoàn thiện nghiên cứu một cách tốt nhất, tuy nhiên, do sự giới hạn về thời gian và kiến thức, nghiên cứu vẫn còn những hạn chế nhất định như cỡ mẫu còn khá ít, phạm vi nghiên cứu chỉ thực hiện trên địa bàn Thành phố Đà Nẵng. Do đó, các nghiên cứu theo sau có thể gia tăng cỡ mẫu và mở rộng phạm vi nghiên cứu trên nhiều tỉnh, thành khác.

\section{Tài liệu tham khảo}

Abd-El-Salam, E. M., Shawky, A. Y., \& El-Nahas, T. (2013). The impact of corporate image and reputation on service quality, customer satisfaction and customer loyalty: Testing the mediating role. Case analysis in an international service company. The Business and Management Review, 3(2), 177-196.

Adam, D. R., Ofori, K. S., Okoe, A. F., \& Boateng, H. (2018). Effects of structural and bondingbased attachment on brand loyalty. African Journal of Economic and Management Studies, 9(3), 305-318.

Afsar, B., Rehman, Z. U., Qureshi, J. A., \& Shahjehan, A. (2010). Determinants of customer loyalty in the banking sector: The case of Pakistan. African Journal of Business Management, 4(6), 1040-1047.

Águila-Obra, A. R. D., Padilla-Meléndez, A., \& Al-dweeri, R. M. O. O. (2013). The influence of electronic service quality on loyalty in postal services: The mediating role of satisfaction. 
Total Quality Management \& Business Excellence, 24(9/10), 1111-1123.

Arshad, T., Zahra, R., \& Draz, U. (2016). Impact of customer satisfaction on image, trust, loyalty and the customer switching behavior in conventional and Islamic banking: Evidence from Pakistan. American Journal of Business and Society, 1(3), 154-165.

Aydin, S., \& Ozer, G. (2005). The analysis of antecedents of customer loyalty in the Turkish mobile telecommunication market. European Journal of Marketing, 39(7/8), 910-925.

Bakar, J. A., Clemes, M. D., \& Bicknell, K. (2017). A comprehensive hierarchical model of retail banking. International Journal of Bank Marketing, 35(4), 662-684.

Bayol, M., Foye, A. D., Tellier, C., \& Tenenhaus, M. (2000). Use of PLS path modelling to estimate the European Consumer Satisfaction Index (ECSI) model. Statistica Applicata, 12(1), 361-375.

Chai, J. C. Y., Malhotra, N. K., \& Alpert, F. (2015). A two-dimensional model of trust-valueloyalty in service relationships. Journal of Retailing and Consumer Services, 26(2015), 23-31.

Chen, S. C. (2015). Customer value and customer loyalty: Is competition a missing link? Journal of Retailing and Consumer Services, 22(C), 107-116.

Ennew, C., \& Sekhon, H. (2007). Measuring trust in financial services: The trust index. Consumer Policy Review, 17(2), 62-68.

Fraering, M., \& Minor, M. S. (2013). Beyond loyalty: Customer satisfaction, loyalty, and fortitude. Journal of Services Marketing, 27(4), 334-344.

Ganiyu, R. A. (2017). Customer satisfaction and loyalty: A study of interrelationships and effects in Nigerian domestic airline industry. Oradea Journal of Business and Economics, 2(1), 7-20.

Gao, L., Waechter, K. A., \& Bai, X. (2015). Understanding consumers' continuance intention towards mobile purchase: A theoretical framework and empirical study - A case of China. Computers in Human Behavior, 53(2015), 249-262.

Hapsari, R., Clemes, M. D., \& Dean, D. (2017). The impact of service quality, customer engagement and selected marketing constructs on airline passenger loyalty. International Journal of Quality and Service Sciences, 9(1), 21-40.

Hartono, M., \& Raharjo, H. (2015). Exploring the mediating role of affective and cognitive satisfaction on the effect of service quality on loyalty. Total Quality Management \& Business Excellence, 26(9/10), 971-985.

Hasan, H., Kiong, T. P., \& Ainuddin, R. A. (2014). Effects of perceived value and trust on customer loyalty towards foreign banks in Sabah, Malaysia. Marketing and Consumer Psychology, 1(2), 137-153.

Hasiri, S. M. A., \& Afghanpour, M. (2016). Investigation of the factors affective on the loyalty of customers in banking industry in the framework of the model of personality characteristics of personnel (Case study: Sepah Bank in Mazandaran province). Procedia Economics and Finance, 36(2016), 490-501.

Herman, H. (2014). The relationship between customer value and customer satisfaction in faceto-face tutorials at Universitas Terbuka. Asian Association of Open Universities Journal, 9(1), 105-114. 
Hoang, T., \& Chu, N. N. M. (2008). Giáo trình phân tích dũ liệu nghiên cứu với SPSS (tập 1 \& 2) [Curriculum analysis of research data with SPSS (episodes 1 \& 2)]. Ho Chi Minh City, Vietnam: Nhà xuất bản Hồng Đức.

Hu, H. H., Kandampully, J., \& Juwaheer, T. D. (2009). Relationships and impacts of service quality, perceived value, customer satisfaction, and image: An empirical study. The Service Industries Journal, 29(2), 111-125.

Hurley, R., Gong, X., \& Waqar, A. (2014). Understanding the loss of trust in large banks. International Journal of Bank Marketing, 32(5), 348-366.

Hussain, R., Nasser, A. A., \& Hussain, Y. K. (2015). Service quality and customer satisfaction of a UAE-based airline: An empirical investigation. Journal of Air Transport Management, 42(1), 167-175.

Irfan, M., Shamsudin, F. M., \& Hadi, N. U. (2016). How important is customer satisfaction? Quantitative evidence from mobile telecommunication market. International Journal of Business and Management, 11(6), 57-69.

Janita, M. S., \& Miranda, F. J. (2013). The antecedents of client loyalty in Business-to-Business (B2B) electronic marketplaces. Industrial Marketing Management, 42(5), 814-823.

Jarvinen, A. R. (2014). Consumer trust in banking relationships in Europe. International Journal of Bank Marketing, 32(6), 551-566.

Jha, S., Deitz, G. D., Babakus, E., \& Yavas, U. (2013). The role of corporate image for quality in the formation of attitudinal service loyalty. Journal of Service Research, 16(2), 155-170.

Kant, R., \& Jaiswal, D. (2017). The impact of perceived service quality dimensions on customer satisfaction: An empirical study on public sector banks in India. International Journal of Bank Marketing, 35(3), 411-430.

Kant, R., Jaiswal, D., \& Mishra, S. (2017). The investigation of service quality dimensions, customer satisfaction and corporate image in Indian public sector banks: An application of structural equation model (SEM). Vision, 21(1), 1-10.

Kaura, V., Prasad, C. S. D., \& Sharma, S. (2014). Impact of service quality, service convenience and perceived price fairness on customer satisfaction in Indian retail banking sector. Management and Labour Studies, 39(2), 127-139.

Keisidou, E., Sarigiannidis, L., Maditinos, D. I., \& Thalassinos, E. I. (2013). Customer satisfaction, loyalty and financial performance: A holistic approach of the Greek banking sector. International Journal of Bank Marketing, 31(4), 259-288.

Keshavarz, Y., \& Jamshidi, D. (2018). Service quality evaluation and the mediating role of perceived value and customer satisfaction in customer loyalty. International Tourism of Tourism Cities, 4(2), 220-244.

Korda, A. P., \& Snoj, B. (2010). Development, validity and reliability of perceived service quality in retail banking and its relationship with perceived value and customer satisfaction. Managing Global Transition, 8(2), 187-205.

Kotler, P., \& Armstrong, G. (2004). Principles of marketing (10th ed.). Upper Saddle River, NJ: Pearson-Prentice Hall.

Kranias, A., \& Bourlessa, M. (2013). Investigating the relationship between service quality and loyalty in Greek banking sector. Procedia Economics and Finance, 5(13), 453-458. 
Lai, F., Griffin, M., \& Babin, B. J. (2009). How quality, value, image, and satisfaction create loyalty at a Chinese telecom. Journal of Business Research, 62(10), 980-986.

Lam, S. Y., Shankar, V., Erramilli, K. M., \& Murthy, B. (2004). Customer value, satisfaction, loyalty, and switching costs: An illustration from a business-to-business service context. Journal of the Academy of Marketing Science, 32(3), 293-311.

Lei, P., \& Jolibert, A. (2012). A three-model comparison of the relationship between quality, satisfaction and loyalty: An empirical study of the Chinese healthcare system. BMC Health Services Research, 12(1), 436-447.

Leninkumar, V. (2017). The relationship between customer satisfaction and customer trust on customer loyalty. International Journal of Academic Research in Business and Social Sciences, 7(4), 450-465.

Lovelock, C., \& Wirtz, J. (2011). Services marketing: People, technology, strategy (7th ed.). Hackensack, NJ: World Scientific Publishing.

Makanyeza, C., \& Chikazhe, L. (2017). Mediators of the relationship between service quality and customer loyalty: Evidence from the banking sector in Zimbabwe. International Journal of Bank Marketing, 35(3), 540-556.

Mumin, Y. A., Nkegbe, P. K., \& Kuunibe, N. (2012). An analysis of customers' loyalty to banks in Ghana. Research Journal of Finance and Accounting, 3(8), 150-158.

Nguyen, T. D., \& Nguyen, T. T. M. (2011). Giáo trình nghiên cúu thị trưòng [Textbooks for market research]. Hanoi, Vietnam: Nhà xuất bản Lao động.

Ofori, K. S., Boakye, K., \& Narteh, B. (2018). Factors influencing consumer loyalty towards 3G mobile data service providers: Evidence from Ghana. Total Quality Management \& Business Excellence, 29(5/6), 580-598.

Omoregie, O. K., Addae, J. A., Coffie, S., Ampong, G. O. A., \& Ofori, K. S. (2019). Factors influencing consumer loyalty: Evidence from the Ghanaian retail banking industry. International Journal of Bank Marketing, 37(3), 798-820.

Pandey, S. K., \& Devasagayam, R. (2012). Responsiveness as antecedent of satisfaction and referrals in financial services marketing: Empirical evidence from an emergent economy. Journal of Applied Business Research, 28(1), 115-132.

Parasuraman, A., Zeithaml, V. A., \& Berry, L. L. (1985). A conceptual model of service quality and its implications for future research. Journal of Marketing, 49(3),41-50.

Parasuraman, A., Zeithaml, V. A., \& Berry, L. L. (1988). Servqual: A multiple-item scale for measuring consumer perception of service quality. Journal of Retailing, 64(1), 12-40.

Pleshko, L. P., \& Heiens, R. A. (2015). Customer satisfaction and loyalty in the Kuwaiti retail services market: Why are satisfied buyers not always loyal buyers? The International Review of Retail, Distribution and Consumer Research, 25(1), 55-71.

Rasheed, F. A., \& Abadi, M. F. (2014). Impact of service quality, trust and perceived value on customer loyalty in Malaysia services industries. Procedia - Social and Behavioral Sciences, 164(2014), 298-304.

Rorio, E. (2013). Factors influencing customer loyalty in the banking sector: A case of commercial banks in Mombasa Kenya. Journal of Business Administration and Management Sciences Research, 53(9), 54-56. 
Saleem, M. A., Zahra, S., \& Yaseen, A. (2017). Impact of service quality and trust on repurchase intentions - The case of Pakistan airline industry. Asia Pacific Journal of Marketing and Logistics, 29(5), 1136-1159.

Schoorman, F. D., Mayer, R. C., \& Davis, J. H. (2007). An integrative model of organizational trust: Past, present, and future. The Academy of Management Review, 32(2), 344-354.

Stan, V., Caemmerer, B., \& Cattan-Jallet, R. (2013). Customer loyalty development: The role of switching cost. The Journal of Applied Business Research, 29(5), 1541-1554.

Sugiati, T., Thoyib, A., Hadiwidjoyo, D., \& Setiawan, M. (2013). The role of customer value on satisfaction and loyalty (Study on Hypermart's customers). International Journal of Business and Management Invention, 2(6), 65-70.

Tang, L. L., \& Nguyen, H. T. H. (2013). Common causes of trust, satisfaction and TAM in online shopping: An integrated model. Journal of Quality, 20(5), 483-501.

Tu, Y. T., Wang, C. M., \& Chang, H. C. (2012). Corporate brand image and customer satisfaction on loyalty: An empirical study of Starbucks Coffee in Taiwan. Journal of Social and Development Sciences, 3(1), 24-32.

Tweneboah-Koduah, E., \& Farley, Y. D. (2015). Relationship between customer satisfaction and customer loyalty in the retail banking sector of Ghana. International Journal of Business and Management, 11(1), 249-262.

Wang, C. Y. (2010). Service quality, perceived value, corporate image, and customer loyalty in the context of varying levels of switching costs. Psychology and Marketing, 27(3), 252-262.

Wu, Y. C., Tsai, C. S., Hsiung, H. W., \& Chen, K. Y. (2015). Linkage between frontline employee service competence scale and customer perceptions of service quality. Journal of Services Marketing, 9(3), 224-234.

Xu, C., Peak, D., \& Prybutok, V. (2015). A customer value, satisfaction, and loyalty perspective of mobile application recommendations. Decision Support Systems, 79(2015), 171-183.

Yang, Z., \& Peterson, R. T. (2004). Customer perceived value, satisfaction, and loyalty: The role of switching costs. Psychology and Marketing, 21(10), 799-822.

Zameer, H., Tara, A., Kausar, U., \& Mohsin, A. (2015). Impact of service quality, corporate image and customer satisfaction towards customers' perceived value in the banking sector in Pakistan. International Journal of Bank Marketing, 33(4), 442-456. 